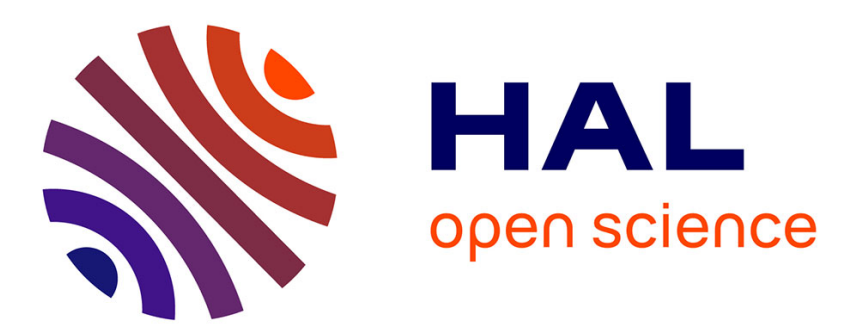

\title{
Combined effects of the filling ratio and the vapour space thickness on the performance of a flat plate heat pipe
}

S. Lips, F. Lefevre, Jocelyn Bonjour

\section{To cite this version:}

S. Lips, F. Lefevre, Jocelyn Bonjour. Combined effects of the filling ratio and the vapour space thickness on the performance of a flat plate heat pipe. International Journal of Heat and Mass Transfer, 2010, 53 (4), pp.694-702. 10.1016/j.ijheatmasstransfer.2009.10.022 . hal-00454396

\section{HAL Id: hal-00454396 https://hal.science/hal-00454396}

Submitted on 8 Mar 2017

HAL is a multi-disciplinary open access archive for the deposit and dissemination of scientific research documents, whether they are published or not. The documents may come from teaching and research institutions in France or abroad, or from public or private research centers.
L'archive ouverte pluridisciplinaire HAL, est destinée au dépôt et à la diffusion de documents scientifiques de niveau recherche, publiés ou non, émanant des établissements d'enseignement et de recherche français ou étrangers, des laboratoires publics ou privés. 


\title{
Combined effects of the filling ratio and the vapour space thickness on the performance of a flat plate heat pipe
}

\author{
Stéphane Lips, Frédéric Lefèvre*, Jocelyn Bonjour \\ Centre de Thermique de Lyon, UMR 5008 CNRS-INSA-UCB \\ INSA, 20 av. A. Einstein, 69621 Villeurbanne Cedex - France
}

\begin{abstract}
An experimental study of a flat plate heat pipe (FPHP) is presented. Temperature fields in the FPHP are measured for different filling ratios, heat fluxes and vapour space thicknesses. The system is hermetically sealed with a transparent plate for meniscus curvature radius observations by confocal microscopy. Experimental results show that the liquid distribution in the FPHP - and thus its thermal performance depends strongly on both the filling ratio and the vapour space thickness. A small vapour space thickness induces liquid retention and thus reduces the thermal resistance of the system. Nevertheless, the vapour space thickness influences the level of the meniscus curvature radii in the grooves and hence reduces the maximum capillary pressure. As a result, it has to be carefully optimised to improve the performance of the FPHP. In all the cases, the optimum filling is in the range one to two times the total volume of the grooves. A theoretical approach, in non working conditions, has been developed to model the distribution of the liquid inside the FPHP in function of the filling ratio and the vapour space thickness.
\end{abstract}

Keywords: flat plate heat pipe; vapour chambers; thin film; capillarity; confocal microscopy

\section{Nomenclature}

a capillary constant, $\mathrm{m}$

$f_{r} \quad$ filling ratio, -

$g \quad$ gravitational acceleration, $\mathrm{m} \mathrm{s}^{-2}$

$H \quad$ thickness, $\mathrm{m}$

$H_{c} \quad$ critical vapour space thickness, $\mathrm{m}$

K constant, -

$l \quad$ width, $\mathrm{m}$

$L \quad$ length of the FPHP, m

$N \quad$ number of grooves, -

$P \quad$ pressure, $\mathrm{Pa}$

$q \quad$ heat flux, $\mathrm{W} \mathrm{m}^{-2}$

$Q \quad$ heat transfer rate, W

$r \quad$ meniscus curvature radius, $\mathrm{m}$

$r_{0} \quad$ meniscus curvature radius for $z=0, \mathrm{~m}$

$R \quad$ thermal resistance, $\mathrm{K} \mathrm{W}^{-1}$

$T$ temperature, $\mathrm{K}$

$V \quad$ volume, $\mathrm{m}^{3}$

$V^{*} \quad$ dimensionless load of liquid, -

$x \quad$ coordinate along the FPHP length, $\mathrm{m}$

$\mathrm{y}$ coordinate across the FPHP width, $\mathrm{m}$

\begin{tabular}{ll}
\multicolumn{2}{l}{ Subscripts } \\
cap & capillary \\
cond & condenser \\
evap & evaporator \\
$\mathrm{g}$ & grooves \\
$\mathrm{l}$ & liquid \\
$\mathrm{max}$ & maximum \\
$\mathrm{min}$ & minimum \\
sat & saturation \\
tot & total \\
$\mathrm{v}$ & vapour
\end{tabular}

$z \quad$ vertical coordinate, $\mathrm{m}$

$\begin{array}{ll}\text { Greek } & \text { symbols } \\ \alpha & \text { contact angle, } \mathrm{rad} \\ \varphi & \text { angle, rad } \\ \psi & \text { central angle, } \mathrm{rad} \\ \rho & \text { density, } \mathrm{kg} \mathrm{m}^{-3} \\ \sigma & \text { surface tension, } \mathrm{N} \mathrm{m}^{-1}\end{array}$

* Corresponding author. Tel.: +33 47243 8251; fax: +33 472438811 .

E-mail address: frederic.lefevre@insa-lyon.fr (F. Lefèvre) 


\section{Introduction}

Flat plate heat pipes (FPHP) and vapour chambers are micro-fluidic devices, that are usually designed for thermal management of electronic components [1,2]. They are used for their heat transfer capacity as well as their capacity of homogenizing the temperature. A FPHP is a cavity of small thickness partially filled with a two-phase working fluid. Heat sources and heat sinks are located anywhere on the cavity with the other parts being insulated. Vapour is generated at the heat source level (evaporator) and it condenses at the heat sink level (condenser). The liquid returns from the evaporator to the condenser through a capillary structure made of micro-grooves, meshes or sintered powder wicks. For the cooling of electronic devices, the more common working fluids are water, methanol, ethanol, acetone or n-pentane.

Since the nineties, a lot of works have been published on those systems and several numerical or analytical models have been proposed in order to predict their thermal performances and/or their capillary limit. These models are generally based on previous works on micro heat pipes (MHP) [35]. Hydrodynamic models of MHP are based on the balance equations and the Young-Laplace law [3,5], which connects liquid and vapour pressures to the meniscus curvature radius in the corners of a MHP. Heat transfer is taken into account by heat conduction in both the wall and the liquid and phase change at the liquid-vapour interface. Interfacial phenomena in the very small region at the junction between the meniscus and the wall are although taken into account [4].

Similar models have been developed for grooved FPHP [6,7], but axial heat conduction in the wall is neglected, whereas it could affect thermal performances [8]. In a previous work [9], we have coupled a hydrodynamic model to a thermal model including both axial heat conduction in the wall and heat transfer by phase change in the evaporator and the condenser. For more complicated capillary structures (mainly meshes, sintered powder wicks or crossed grooves), such an approach is not possible and the flow in the capillary structure is modelled by the Darcy's law in 2D [8] or 3D $[10]$.

Although there is an important literature on FPHP, experimental papers are relatively rare and do not provide measurements inside these systems, but only surface temperature measurements [11-12]. Furthermore, theoretical works are abundant, but generally focus on capillary-driven flows [6-10] and thermal models in ideal conditions, i.e. the system being optimally filled with liquid. Recently [9,13], we have presented and validated such a model with both surface temperature measurements and meniscus curvature radius measurements inside a grooved capillary structure. Confocal microscopy was used to visualize menisci in the grooves through a transparent plate. The 
FPHP under investigation was made of copper and filled with methanol. It had a wide evaporating area $\left(190 \times 90 \mathrm{~mm}^{2}\right)$ compared to the condenser area $\left(30 \times 90 \mathrm{~mm}^{2}\right)$. As a result the capillary limit was observed for a rather small heat flux $\left(0.9 \mathrm{Wcm}^{-2}\right)$. In this paper, we show that a parameter is not known and has to be determined experimentally to solve the numerical model: the value of the meniscus curvature radius at the end of the condenser. There is a lack of predicting models in the literature to calculate this parameter.

In a more recent paper [14], a similar experiment was developed for a smaller FPHP, made of copper and filled with methanol, with characteristics close to typical FPHPs for electronic cooling. Nucleate boiling was observed for relatively small heat fluxes $\left(3 \mathrm{Wcm}^{-2}\right)$. In this paper, we have shown that the onset of nucleate boiling improves the thermal performance of the flat heat pipe, and does not constitute an operation limit as it is generally stated. The dry out of the evaporator is observed for heat fluxes much higher than the heat flux of onset of nucleate boiling. These experimental results show that a better understanding of these phenomena is necessary, particularly in order to theoretically predict the operation limit in case of nucleate boiling.

In this communication, we present new experimental results that show the combined effects of the filling ratio and the vapour space thickness on the performance of a flat plate heat pipe. We show that these parameters act on both the capillary limit and the thermal resistance of the system. The FPHP under investigation is similar to the one studied in [14]: a transparent plate allows visualization inside the device. Temperature measurements are obtained for different liquid charges and vapour space thicknesses. A confocal microscope is used to measure the menisci curvature radii in the grooves. A theoretical model, developed in non working conditions, is presented and validated with the experimental data.

\section{Experimental set-up}

The flat heat pipe under investigation is shown in figure 1. It has already been described in a previous article [14] that can be read for further details. Its capillary structure, covering an area of $70 \times 90 \mathrm{~mm}^{2}$, is made of 88 longitudinal micro-grooves, machined in a copper plate. The grooves are connected at the condenser. Each groove has a rectangular cross-section of height and width equal to $400 \mu \mathrm{m}$. The distance between two grooves is equal to $400 \mu \mathrm{m}$. The wall thickness under the grooves is equal to $3 \mathrm{~mm}$.

The FPHP is hermetically sealed on its upper face with a transparent plate, which allows the observation of the liquid/vapour menisci in the grooves. A nitrile ring is placed between the copper and the transparent plates to ensure tightness. The vapour space thickness is changed using rings of 
different thicknesses. In this article, three vapour space thicknesses are studied: $H_{\mathrm{v}}=1 \mathrm{~mm}$, $H_{\mathrm{v}}=2 \mathrm{~mm}$ and $H_{\mathrm{v}}=5 \mathrm{~mm}$. A filling copper pipe closed by a valve is sealed on the grooved plate at the extremity of the condenser. The heat source is located on the copper wall. It is a heated copper block of dimensions $70 \times 20 \mathrm{~mm}^{2}$ supplied by a $0-220 \mathrm{~V}$ AC power supply. Electric power is obtained by measuring the voltage drop across the heating resistor and the current, thanks to a calibrated resistance. Thus, the uncertainty due to the power measurement is negligible. The heat sink is a water heat exchanger of dimensions $30 \times 70 \mathrm{~mm}^{2}$. The water flow rate is constant and the inlet temperature is controlled by means of a thermostatic bath in order to have a constant working temperature when the heat input increases. The heat source and the heat sink are separated by an adiabatic area of length equal to $40 \mathrm{~mm}$. Two series of nine calibrated thermistors (uncertainty lower than $0.2 \mathrm{~K}$ ) are located symmetrically along the FPHP wall. They are fixed thanks to silver lacquer in small grooves that were machined in the wall in order to reduce the contact resistance (figure 1). The value of their resistance is recorded by a Keithley 2700 multimeter. The working temperature of the FPHP is the saturation temperature $T_{\text {sat }}$, which is determined as the mean temperature of the six thermistors located in the middle of the adiabatic zone.

The FPHP is thermally insulated during thermal tests. Before thermal tests, the FPHP has to be degassed and filled. In order to promote surface wetting, the copper plate is first cleaned. The FPHP and the working fluid n-pentane are degassed carefully to eliminate non-condensable gases. The method of evacuating the non-condensable gases from the working fluid is based on fluid solidification under vacuum. The fluid contained in a heated vessel vaporizes, releases noncondensable gases and solidifies in a second vessel dipped into liquid nitrogen. The noncondensable gases are evacuated by vacuum pumps. The FPHP is degassed by heating during vacuum pumping at $10^{-5}$ mbar.

In working conditions, vapour is generated at the evaporator and it condenses at the condenser. The liquid returns from the evaporator to the condenser through the capillary structure made of micro-grooves. In the grooves the liquid makes a meniscus, which curvature radius varies from the evaporator to the condenser due to the pressure drop inside the system. Thus measuring the meniscus curvature radius is a way of measuring a hydrodynamic parameter inside the capillary structure.

A confocal microscope is used to measure the meniscus curvature radius in the grooves, the FPHP being in horizontal orientation. The confocal microscope is a STIL Micromesure 2 system. The optical sensor has a nominal measuring range of $350 \mu \mathrm{m}$. The working distance is about 13 $\mathrm{mm}$. The maximum measuring angle for specular reflection is equal to $27.4^{\circ}$. The optical sensor 
velocity is about $1 \mathrm{~mm} \mathrm{~s}^{-1}$, which is fast enough for not thermally disturbing the measurement. Once the top of the groove is located by the sensor, the surface profile is recorded. The resulting data are used to estimate through a least square method the radius and the coordinates of the centre of a circle that fits at best the experimental data. More details about confocal microscopy applied to characterization of FPHP can be found in $[9,15]$.

\section{Experimental results}

The FPHP, filled with n-pentane, has been tested in horizontal orientation at a saturation temperature equal to $40^{\circ} \mathrm{C}$. Temperatures are measured in steady state at successively decreasing filling ratios for a given heat flux. Thermal characterizations have been performed with three different heat fluxes and with three different vapour space thicknesses. Meniscus curvature measurements by confocal microscopy are presented to complete temperature measurements.

Although the FPHP is thermally insulated, thermal losses lead to experimental uncertainties. In the present experimental conditions, they have been estimated to be lower than $3 \mathrm{~W}$ for a saturation temperature of $40^{\circ} \mathrm{C}$. As a consequence, the relative uncertainty is low: about $5 \%$ for a heat flux of $5 \mathrm{~W} / \mathrm{cm}^{2}$.

\subsection{Determination of an optimal filling ratio for a constant vapour space}

In this section, the vapour space is constant and equal to $2 \mathrm{~mm}$. Temperature fields in the FPHP have been recorded for three different heat fluxes and for different filling ratios. The filling ratio $f_{\mathrm{r}}$ is the ratio between the volume of liquid and the internal volume of the FPHP. For $f_{\mathrm{r}}=0$, the FPHP is empty and for $f_{\mathrm{r}}=1$, the FPHP is full of liquid. Experimentally, $f_{\mathrm{r}}$ is determined by measuring the liquid height in the FPHP in vertical position at $40^{\circ} \mathrm{C}$. Results obtained for a heat flux of $7.5 \mathrm{~W} / \mathrm{cm}^{2}$ are presented in figure 2 , which shows the temperature profile as a function of location along $\mathrm{x}$ axis (as defined in figure 1).

The thermal performance of the flat heat pipe can be characterized by the overall thermal resistance $R_{\mathrm{tot}}=\left(T_{\max }-T_{\min }\right) / Q$, as well as by the condenser and the evaporator thermal resistances $R_{\text {cond }}=\left(T_{\text {sat }}-T_{\min }\right) / Q$ and $R_{\text {evap }}=\left(T_{\max }-T_{\text {sat }}\right) / Q$ respectively. The overall thermal resistance results from the combination of both the condenser and the evaporator thermal resistances. 
Figures 3 to 5 show the condenser, evaporator and overall thermal resistances versus the filling ratio for different heat fluxes. Thermal resistances depend strongly on the filling ratio: for small $f_{\mathrm{r}}$, dryout of the evaporator occurs and for high $f_{\mathrm{r}}$, the condenser is flooded. In both cases, heat transfer coefficients at the evaporator and the condenser are small. As a result, there exists an optimal filling ratio that optimises the thermal performance i.e. that minimizes the overall thermal resistance. For a vapour space thickness $H_{\mathrm{v}}=2 \mathrm{~mm}$, optimal values of $f_{\mathrm{r}}$ are in the range $10 \%$ to $25 \%$, which corresponds to a liquid quantity inside the system equal to 1 . to 2.5 times the total volume of the grooves.

The increase of the heat flux does not affect the condenser thermal resistance (figure 3), which depends only of the percentage of area which is flooded by the liquid. On the contrary, the increase of the heat flux decreases the range of filling ratio for which the evaporator thermal resistance is the lowest. Indeed, at high heat fluxes a higher filling ratio is necessary to prevent dry out: the distance between the evaporator and the liquid stored at the condenser decreases when the filling ratio increases. Optimal filling ratios are similar at the evaporator and the condenser for small heat fluxes $\left(q \leq 7.5 \mathrm{Wcm}^{-2}\right)$, but not for $q=10 \mathrm{Wcm}^{-2}$. As a result, the overall thermal resistance is higher for $q$ $=10 \mathrm{Wcm}^{-2}$ (figure 5) than for low heat fluxes.

\subsection{Effect of the vapour space thickness on the thermal resistance}

In this section, we present $R_{\text {evap }}$ and $R_{\text {cond }}$ versus the filling ratio for three vapour space thicknesses $\left(H_{\mathrm{v}}=1 \mathrm{~mm}, H_{\mathrm{v}}=2 \mathrm{~mm}\right.$ and $\left.H_{\mathrm{v}}=5 \mathrm{~mm}\right)$ and three heat fluxes $\left(q=5 \mathrm{Wcm}^{-2}, q=7.5\right.$ $\mathrm{Wcm}^{-2}$ and $q=10 \mathrm{Wcm}^{-2}$ ). Figures 6 and 7 present the condenser thermal resistance for these parameters. For small vapour space thicknesses, the increase of $H_{\mathrm{v}}$ does not noticeably modify $R_{\text {cond }}$ until a limit thickness is reached (this limit is discussed in part 3). For higher vapour space thicknesses, the condenser characteristics change: the decrease of the thermal resistance towards its optimal value is much stiffer than for high $H_{\mathrm{v}}$. In other words, an only very small range of filling ratios provides small thermal resistances. These two different characteristics are linked to liquid location inside the system. For small vapour spaces, capillary effects are important and the liquid in excess is confined between the upper and lower plates of the FPHP. Thus, the liquid is not homogeneously distributed on the copper plate, but is located on the corners of the system and in the grooves. For high vapour spaces, gravity forces are preponderant and if the volume of liquid inside the FPHP exceeds the volume of the grooves, the liquid is homogeneously distributed on the copper plate, which induces higher thermal resistances. As a conclusion, a thick vapour space is 
interesting to reduce the vapour pressure drop (because of lower vapour velocities), but it prevents the liquid retention effects that are useful to limit the condenser thermal resistance.

Figures 8 and 9 present $R_{\text {evap }}$ for $H_{\mathrm{v}}$ equal to 1 and $2 \mathrm{~mm}$, and $5 \mathrm{~mm}$, respectively. For $H_{\mathrm{v}}=5 \mathrm{~mm}$, the evaporator thermal resistance is very similar to the condenser thermal resistance: the liquid distribution in the FPHP is mainly induced gravitational forces. For vapour spaces of 1 and $2 \mathrm{~mm}$, the optimal filling ratio strongly depends on the heat flux and on the vapour space. Indeed, the increase of the heat flux increases pressure drops in the liquid and vapour phases, which can lead to the dry out of the evaporator. Furthermore, the maximum capillary pressure in the capillary structure strongly depends on the filling ratio and the vapour space thickness as it is shown by confocal microscopy measurements in next section.

For a vapour space thickness $H_{\mathrm{v}}=5 \mathrm{~mm}$, optimal values of $f_{\mathrm{r}}$ are in the range $4 \%$ to $8 \%$, which corresponds to a liquid quantity inside the system equal to 1 . to 2 . times the total volume of the grooves. For $H_{\mathrm{v}}=1 \mathrm{~mm}$, optimal values of $f_{\mathrm{r}}$ are above $17 \%$, the value of $f_{\mathrm{r}}$ for which the liquid quantity is equal to the volume of the grooves. A similar remark was made for $H_{\mathrm{v}}=2 \mathrm{~mm}$ with optimal filling ratio in the range 1 . to 2.5 times the total volume of the grooves. Thus, a slight overfilling (until 2. times the total volume of the grooves) is necessary to obtain the best thermal performance. Compare to micro heat pipes, in which the liquid quantity can be calculated easily with the hydrodynamic equations [4], in FPHP such models [6,7,9] would underestimate the liquid quantity inside the system. Indeed, a part of the liquid is trapped on the four sides of the FPHP because of the capillary forces.

\subsection{Combined effects of the filling ratio and the vapour space thickness on the maximum capillary pressure}

The meniscus curvature radii in the grooves vary from the condenser to the evaporator because of pressure drops in both liquid and vapour flows. However, it has to be noticed that for a given total pressure drop, an infinity of meniscus curvature radius profiles can be found. The value of the curvature radius at the condenser (at $x=0$ ) determines the mean level of the meniscus curvature radii all along the grooves. The higher the meniscus curvature radius at the condenser is and the higher the meniscus curvature radii all along the grooves are. In the next sections, we call "level of curvature radius" the mean value of the curvature radii in the groove due to the value of the curvature radius at the condenser. The level of curvature radius has important consequences on the FPHP performance. Small radii at the condenser lead to thin liquid films in the grooves and thus 
reduce thermal resistances. Nevertheless, it reduces the maximum capillary pressure inside the system and thus the maximum heat transfer rate, as it is shown in this section.

Meniscus curvature radii are measured with the confocal microscope along the grooves, the FPHP being in horizontal location. Measurement standard deviation of the radii in different grooves at a given $x$ location is typically $100 \mu \mathrm{m}$. Hence, the presented results are the average measurements in 13 grooves. FPHP extremities cannot be observed, because the FPHP enclosure prevents the optical sensor positioning. Thus, the grooves can only be observed from $x=15 \mathrm{~mm}$ to $x=75 \mathrm{~mm}$.

Figures 10 and 11 present meniscus curvature radii along the grooves for filling ratios of $9 \%$ and $13 \%$ respectively. The vapour space thickness is equal to $2 \mathrm{~mm}$ and results are obtained with heat fluxes varying from $0 \mathrm{Wcm}^{-2}$ to $6.3 \mathrm{Wcm}^{-2}$. The level of meniscus curvature radii increases with the increase of the filling ratio. In non working conditions, the meniscus curvature radius is about $1.5 \mathrm{~mm}$ for $f_{\mathrm{r}}=9 \%$ and it reaches $2.2 \mathrm{~mm}$ for $f_{\mathrm{r}}=13 \%$. Thus, the filling ratio has to be taken into account to model meniscus curvature variations along the grooves and the resulting temperature field. The dependency to the level of the meniscus curvature radius with the filling ratio is theoretically studied in part 3. For a fixed filling ratio, it appears that there is a location in the FPHP where the meniscus curvature radius is constant whatever the heat flux. This particular position is close to the middle of the condenser in this experiment. In [13], Rulliere et al. found a similar particular position that was located in the adiabatic zone.

Figure 12 presents meniscus curvature radii along the grooves for vapour spaces of $1 \mathrm{~mm}$ and $2 \mathrm{~mm}$ respectively. The liquid load is similar in both cases and equal to $1.1 \mathrm{ml}$. Thus, $f_{\mathrm{r}}$ is higher for $H_{\mathrm{v}}=1 \mathrm{~mm}$ than for $H_{\mathrm{v}}=2 \mathrm{~mm}$ and equal to $18 \%$ and $9 \%$ respectively. The vapour space thickness has a strong influence on the level of the meniscus curvature radius inside the system. Indeed, for small $H_{\mathrm{v}}$, the liquid is confined between the two FPHP plates and forms a meniscus whose curvature radius decreases with the decrease of $H_{\mathrm{v}}$. As a result, a small meniscus curvature is imposed at the condenser. Although this effect is interesting from a thermal point of view, it strongly reduces the maximum capillary pressure inside the capillary structure as it is shown in part 3. This result explains the dry out observed for smaller heat fluxes when $H_{\mathrm{v}}$ decreases (figure 8). Thus, the liquid retention effects that occur for small vapour spaces and limit the condenser thermal resistance also lead to a smaller capillary pressure difference in a FPHP.

\section{Theoretical analysis of vapour space thickness and filling ratio effects on FPHP performance}


As shown previously, both the vapour space thickness and the filling ratio have a strong influence on the thermal performances of the FPHP. In order to analyse these phenomena, theoretical models have to be developed to calculate the liquid distribution in the FPHP.

\subsection{Effect of the filling ratio on the liquid distribution}

The distribution of the liquid inside a FPHP is the result of capillary forces, gravitational forces and pressure gradients in the liquid and vapour phases due to the fluid flow. In non working conditions, the fluid is at rest, and thus only capillary and gravitational forces act on the liquid distribution.

Figure 13 shows various theoretical liquid distributions in a FPHP at rest as a function of the liquid charge, in a 2D cross section. Boundary effects are neglected and the liquid wettabillity is supposed to be high (contact angle lower than $45^{\circ}$, which is the case for methanol or n-pentane on a copper plate, otherwise configurations (a) and (b) are different). For a low filling ratio, the liquid remains in the corner of the grooves: the meniscus curvature radii are small (a). Increasing the filling ratio increases the curvature radius of the two menisci in the groove corners until a single meniscus is formed (b). Then, the curvature radius remains constant until the meniscus reaches the top of the grooves (c) and a meniscus is formed on both sides of the FPHP (d). If the vapour space is small enough, the meniscus reaches the upper plate (e). Then, for higher filling ratios, the volume of liquid increases, and the curvature radius remains constant (f). But if the vapour space is too high, gravitational effects induce a homogeneous distribution of the liquid in the FPHP until the distance between the liquid and the upper plate is small enough to have a meniscus in touch with the upper plate (e' and f').

When a meniscus is formed between the two plates of a FPHP, it acts on both the condenser thermal performance and the capillary limit. Its shape is a function of the vapour space thickness, and can be determined by considering both capillary and gravitational forces.

\subsection{Shape of the meniscus between the two plates of the FPHP}

The shape of the meniscus between the two plates of a FPHP at rest is governed by gravitational and capillary forces. The Young-Laplace law introduces capillary pressure versus the curvature radius $r(z)$ at each point of the meniscus. By neglecting the meniscus curvature along the $x$ axis, we have: 
$P_{l}(z)=P_{v}-\frac{\sigma}{r(z)}$

where $P_{1}$ and $P_{\mathrm{v}}$ are the liquid and vapour pressures respectively, $\sigma$ the surface tension, and $z$ the vertical coordinate. The intercept point $z=0$ is located at the bottom of the plate, above the grooves (Figure 14). Gravitational forces induce:

$P_{l}(z)=-\left(\rho_{l}-\rho_{v}\right) g z+P_{l}(z=0)$

where $\rho$ is the density and $g$ the gravity acceleration. At $z=0$, the meniscus curvature radius is equal to the meniscus curvature radius in the grooves $r_{0}$, which is constant in all the grooves because they are connected at the condenser. Thus:

$P_{l}(z=0)=P_{v}-\frac{\sigma}{r_{0}}$

By introducing equations (1) and (3) in equation (2), capillary and gravitational forces are linked together:

$\frac{\sigma}{r_{0}}-\frac{\sigma}{r(z)}=-\left(\rho_{l}-\rho_{v}\right) g z$

Equations (4) can be written:

$$
r(z)=\frac{1}{\frac{1}{r_{0}}+\frac{2 z}{a^{2}}} \text { with } a^{2}=\frac{2 \sigma}{\left(\rho_{l}-\rho_{v}\right) g}
$$

where $a$ is the so called capillary constant of the fluid.

Let us introduce the angle $\varphi$ between the tangent to the meniscus and the $y$ axis. The meniscus curvature radius can be expressed:

$$
r(z)=\frac{d z}{\sin \varphi d \varphi}
$$

By introducing equation (5) in equation (6), we obtain:

$$
\left(\frac{2 z}{a^{2}}+\frac{1}{r_{0}}\right) d z=\sin \varphi d \varphi
$$

The integration of equation (7) leads to:

$$
\left(\frac{z}{a}\right)^{2}+\frac{z}{r_{0}}=-\cos \varphi+K
$$

where $K$ is a constant depending on $\alpha_{0}$ (i.e. the contact angle between the liquid and the bottom plate: $K=\cos \alpha_{0}$ ), which is assumed to be equal to the wetting angle between the fluid and the wall. By introducing $K$ into equation (8), we obtain the equation of the meniscus shape:

$$
\left(\frac{z}{a}\right)^{2}+\frac{z}{r_{0}}=\cos \alpha_{0}-\cos \varphi
$$


whose physical solution is:

$$
z=\sqrt{\left(\frac{a^{2}}{2 r_{0}}\right)^{2}+a^{2}\left(\cos \alpha_{0}-\cos \varphi\right)}-\frac{a^{2}}{2 r_{0}}
$$

In equation (10), the meniscus curvature radius $r_{0}$ is an unknown, which can be obtained by considering the contact angle $\alpha_{1}$ between the meniscus and the upper plate at $z=H_{\mathrm{v}}$ :

$$
r_{0}=\frac{H_{v}}{\cos \alpha_{0}+\cos \alpha_{1}-\left(\frac{H_{v}}{a}\right)^{2}}
$$

As a result, $r_{0}$ depends of the vapour space thickness, the contact angles between the meniscus and the bottom and upper plates, and the fluid capillary number.

Figure 15 presents the shape of the meniscus between the two plates of the FPHP for different vapour spaces. The shape is calculated numerically by introducing equation (11) into equation (10). Thus, $z$ is a function of $H_{\mathrm{v}}$ and $\varphi$, the angle between the meniscus and the $y$ axis. The fluid is n-pentane. Its capillary number is about $2 \mathrm{~mm}$ and the contact angles are assumed to be equal to $2^{\circ}$. For small vapour spaces, gravitational effects are negligible and the shape of the meniscus is half a circle. For thicker vapour spaces, gravitational forces act on the shape of the meniscus until a critical vapour space thickness $H_{\mathrm{c}}$ for which the capillary forces are not sufficient to maintain the meniscus between the two plates. $H_{\mathrm{c}}$ is obtained when $r_{0}$ tends to an infinite value:

$$
H_{c}=a \sqrt{\cos \alpha_{0}+\cos \alpha_{1}}
$$

If the contact angles are equal to zero, $H_{c}=a \sqrt{2}$. For increasing contact angles, the critical vapour space thickness decreases.

Thermal consequences of the presence of the meniscus between the two plates of a FPHP are noticeable as is has been shown in part 2. Indeed, for a vapour space smaller than the critical vapour space, the liquid is drained to the FPHP sides, which reduces the thermal resistance at both the evaporator and the condenser. For a vapour space thicker than $H_{\mathrm{c}}$, if the volume of liquid is higher than the volume of the grooves, the capillary structure is flooded, which increases the overall thermal resistance.

As a conclusion, if the vapour space is small enough $\left(H_{\mathrm{v}}<H_{\mathrm{c}}\right), f_{\mathrm{r}}$ can be increased to a certain extent without increasing to much the thermal resistance. On the contrary, if $H_{\mathrm{v}}>H_{\mathrm{c}}$, an increase of 
$f_{\mathrm{r}}$ is an abrupt increase of the thermal resistance. Nevertheless, we will show in the next sections that a too small vapour space leads to a low maximal capillary pressure, which is not desirable.

\subsection{Meniscus curvature radius in the grooves in non working conditions}

As indicated previously, the grooves are linked together at the condenser end. As a result, in non working conditions, $r_{0}$ is constant all over the capillary structure. In cases of figure 13 (e) and (f), the value of $r_{0}$ is linked to the vapour space thickness, the contact angles between the meniscus and the two plates, and the fluid capillary number (equation (5)). Figure 16 presents $r_{0}$ versus the vapour space thickness, for $n$-pentane, with contact angles equal to $2^{\circ}$. This curve has two asymptotes:

For small vapour spaces, gravity forces are negligible and $r_{0}$ is constant along the $z$ axis: $r_{0}(z)=\frac{H_{v}}{\cos \alpha_{0}+\cos \alpha_{1}}$

The second asymptote is vertical and corresponds to $H_{\mathrm{v}}=H_{\mathrm{c}}$ (equation (12)).

When a meniscus exists between the two plates of the FPHP (figure 13 (e) and (f)), the meniscus curvature radius in the grooves does not depend on the filling ratio and is equal to $r_{0}$. For smaller filling ratios (figure 13 (a) to (d)), it depends on the filling ratio and is lower than $r_{0}$. Geometrical considerations allow calculating its value as a function of the liquid volume $V_{1}$ in the FPHP.

For $r<l_{\mathrm{g}} / 2$, two menisci are located in the corner of the grooves (Figure 13 (a) and (b)), and thus the volume of the liquid is calculated geometrically by considering a wetting angle equal to zero. Note that the wetting angle could be introduced easily in the model. The two menisci located on each side of the FPHP are taken into account similarly for the liquid volume calculation. Thus, $V_{1}$ is expressed as:

$V_{l}=L(2 N+2)\left(1-\frac{\pi}{4}\right) r^{2}$

where $l_{\mathrm{g}}$ is the groove width, $N$ is the number of grooves and $L$ the FPHP length.

For $l_{\mathrm{g}} / 2<r<r_{0}$ (Figure 13 (c)and (d)), the meniscus curvature radius is attached to the top of the groove and varies from a value equal to $l_{\mathrm{g}} / 2$ to an infinite value. $V_{1}$ is calculated considering these geometrical considerations: 
$V_{l}=L\left(N\left(l_{g} h_{g}-r^{2}\left(\psi-\frac{\sin (2 \psi)}{2}\right)\right)+2\left(1-\frac{\pi}{4}\right) r^{2}\right) \quad$ with $\psi=\arcsin \left(\frac{l_{g}}{2 r}\right)$

where $h_{\mathrm{g}}$ is the groove height and $2 \psi$ the central angle formed by the arc of circle of radius $r$ (i.e. the meniscus) in the groove.

Figure 17 presents the evolution of the meniscus curvature radius in the grooves as a function of the dimensionless volume of liquid $V^{*}$ inside the FPHP for different vapour space thicknesses. $V^{*}$ is the ratio between the volume of liquid in the FPHP and the volume of the grooves. Theoretical results, obtained with the above equations, are represented by continuous lines. Experimental data, obtained by confocal microscopy in non working conditions are plotted with crosses and squares on the same figure. A relatively good agreement is observed between theoretical and experimental results. For $H_{\mathrm{v}}>2 \mathrm{~mm}$ and $V^{*}>1, r_{0}$ increases slightly with an increase of $V^{*}$ from $V^{*}=1$ to $V^{*}=5$, and crosses the predicted value (i.e. $r_{0}=2 \mathrm{~mm}$, which is supposed to be constant) for $V^{*}=3$. Nevertheless, as $r_{0}$ is relatively high in that case, this variation does not lead to a big variation of the capillary pressure, which is inversely proportional to $r_{0}$.

It has to be noticed that these results are not useful in working conditions for $V^{*}<1$. Indeed, we have seen in the previous parts that the best performance where obtained for filling ratios higher than the volume of the grooves (i.e. $V^{*}>1$ ). In working conditions $\mathrm{V}^{*}<1$ leads to a dry out of the evaporator for small heat fluxes. Nevertheless, results of figure 17 validate our assumptions and derivations.

\subsection{Consequences on the maximum capillary pressure}

Capillary limit is the principal limit encountered in a FPHP in usual conditions. It appears when the sum of the liquid and vapour pressure drops exceeds the maximum capillary pressure that a capillary structure can sustain. In general, the maximum capillary pressure in a grooved system is given by [16]:

$$
\Delta P_{\text {cap }}=\frac{\sigma}{\left(r_{\text {evap }}\right)_{\min }}
$$

assuming an infinite meniscus curvature radius at the condenser and where $\left(r_{\text {evap }}\right)_{\min }$ is the minimum curvature radius at the evaporator. We have shown in previous sections that a small vapour space thickness leads to a reduced meniscus curvature radius in the system in non working conditions. In working conditions, it leads to a reduced maximal meniscus curvature radius at the condenser and thus lowers the maximal capillary pressure: 
$\Delta P_{\text {cap }}=\sigma\left(\frac{1}{\left(r_{\text {evap }}\right)_{\min }}-\frac{1}{\left(r_{\text {cond }}\right)_{\max }}\right)$

Measurements presented in figure 12 confirm these assumptions. Indeed, with a vapour space equal to $1 \mathrm{~mm}$, the level of curvature radii inside the capillary structure is much smaller than that obtained for $H_{\mathrm{v}}=2 \mathrm{~mm}$.

As a result, the optimal liquid load in a FPHP is the lowest load which leads to the maximum meniscus curvature radius at the condenser. Indeed, excess liquid induces a partial flooding of the FPHP and as a consequence increases the thermal resistance, whereas a lack of liquid induces a decrease of the maximum capillary pressure. Equation (16) can be written as:

$\Delta P_{\text {cap }}=\frac{\sigma}{\left(r_{\text {evap }}\right)_{\min }}\left(1-\frac{\left(r_{\text {evap }}\right)_{\min }}{\left(r_{\text {cond }}\right)_{\max }}\right)$

with $\frac{\left(r_{\text {evap }}\right)_{\min }}{\left(r_{\text {cond }}\right)_{\max }}$, the depreciation factor of the maximum capillary pressure due to the vapour space thickness.

In a FPHP with rectangular grooves $\left(r_{\text {evap }}\right)_{\min }=\frac{l_{g}}{2 \cos \alpha_{0}}[16] .\left(r_{\text {cond }}\right)_{\max }$ is given by equation (11) in non working conditions. In working conditions, this equation is slightly modified by condensation phenomena and liquid flow in the grooves. Nevertheless, equation (11) is a good approximation of $\left(r_{\text {cond }}\right)_{\max }$. Thus, we obtain:

$$
\frac{\left(r_{\text {evap }}\right)_{\min }}{\left(r_{\text {cond }}\right)_{\max }}=\frac{l_{g}}{2 \cos \alpha_{0} H_{v}}\left(\cos \alpha_{0}+\cos \alpha_{1}-\left(\frac{H_{v}}{a}\right)^{2}\right)
$$

For contact angles equal to zero, this equation becomes:

$$
\frac{\left(r_{\text {evap }}\right)_{\min }}{\left(r_{\text {cond }}\right)_{\max }}=\frac{l_{g}}{H_{v}}\left(1-\left(\frac{H_{v}}{a \sqrt{2}}\right)^{2}\right)
$$

Two non-dimensional parameters appear in this expression: the first is the ratio $l_{\mathrm{g}} / H_{\mathrm{v}}$ which represents the relative effects of capillary forces on the sides of the FPHP compared to the capillary forces in the grooves. The second term is $H_{v} / a \sqrt{2}$ and illustrates the confinement of the liquid between the upper and the bottom plates of the FPHP.

The depreciation factor must be minimized to optimise a FPHP. As an example, with our geometry and assuming contact angles equal to $2^{\circ}$, a vapour space of $1 \mathrm{~mm}$ leads to a $35 \%$ decrease of the maximum capillary pressure with respect to an infinite vapour space thickness. 


\section{Conclusion}

A FPHP with rectangular micro-grooves and filled with n-pentane has been studied in horizontal position. Experimental results show that the vapour space thickness and the heat flux have important consequences on the thermal performances of a FPHP. Two different liquid distributions in a FPHP can be observed, depending on the size of the vapour space. A small vapour space thickness induces liquid retention in the FPHP sides and corners and thus reduces the thermal resistance of the system even for a liquid quantity greater than the optimum value. On the contrary, if the vapour space is higher than a critical value, gravitational forces dominate and the capillary structure can be easily flooded if the filling ratio is too high. In that case, the thermal resistance will be high, and thus, the range of optimal liquid charge is very small.

The vapour space thickness influences the level of the meniscus curvature radii in the grooves and hence modifies the maximum capillary pressure. Indeed, a narrow vapour space induces a low maximum meniscus curvature radius at the condenser, which reduces the maximum capillary pressure. The filling ratio and the vapour space thickness have to be carefully optimised in order to improve the thermal and hydrodynamic performances of the system. A theoretical model has been developed in non working conditions to analyse these experimental data. A perspective of this paper is to extend this model in working conditions.

\section{Acknowledgment}

This work was supported by the GIP-ANR in the frame of the non-thematic project "INTENSIFILM" N ANR-06-BLAN-0119-03.

\section{References}

[1] M. Lallemand, F. Lefèvre, Micro/mini heat pipes for the cooling of electronic devices, 13th International Heat Pipe Conference, Shanghaï, China (2004) 12-22.

[2] L.L. Vasiliev, Micro and miniature heat pipes - Electronic component coolers, Appl. Therm. Eng. 28 (2008) 266-273.

[3] J.P. Longtin, B. Badran, F.M. Gerner, A one-dimensional model of a micro heat pipe during steady-state operation, J. Heat Transfer 116 (1994) 709-715.

[4] V. Sartre, M.C. Zaghdoudi, M. Lallemand, Effect of interfacial phenomena on evaporative heat transfer in micro heat pipes, Int. J. Thermal Sciences 39 (2000) 498-504. 
[5] S. Launay, V. Sartre, M. Mantelli, K.V. De Paiva, M. Lallemand, Investigation of a wire plate micro heat pipe array, Int. J. Thermal Sciences 43 (2004) 499-507.

[6] D. Khrustalev, A. Faghri, Coupled liquid and vapor flow in miniature passages with micro grooves, J. Heat Transfer 121 (1999) 729-733.

[7] S.J. Kim, J.K. Seo, K.H. Do, Analytical and experimental investigation on the operational characteristics and the thermal optimization of a miniature heat pipe with a grooved wick structure, Int. J. Heat Mass Transfer 46 (2003) 2051-2063.

[8] F. Lefèvre, M. Lallemand, Coupled thermal and hydrodynamic models of flat micro heat pipes for the cooling of multiple electronic components, Int. J. Heat and Mass Transfer 49 (2006) 1375-1383.

[9] F. Lefèvre, R. Rullière, Guillaume Pandraud, M. Lallemand, Prediction of the temperature field in flat heat pipes with micro-grooves - Experimental validation, Int. J. Heat Mass Transfer 51 (2008) 4083-4094.

[10] B. Xiao, A. Faghri, A three-dimensional thermal-fluid analysis of flat heat pipes, Int. J. Heat Mass Transfer 51 (2008) 3113-3126

[11] Y. Cao, M. Gao, Experiments and analyses of flat miniature heat pipes, J of Thermophysics and Heat Transfer 11 (2) (1997) 158-164.

[12] R. Hopkins, A. Faghri, D. Khrustalev, Flat miniature heat pipes with micro capillary grooves, J of Heat Transfer 121 (1999) 102-109.

[13] R. Rullière, F. Lefèvre, M. Lallemand, Prediction of the maximum heat transfer capability of two-phase heat spreaders - Experimental validation, Int. J. Heat Mass Transfer 50 (2007) 1255-1262.

[14] S. Lips, F. Lefèvre, J. Bonjour, Nucleate boiling in a flat grooved heat pipe, Int. J. Therm. Sci, 48 (2009) $1273-1278$

[15] F. Lefèvre, R. Rullière, S. Lips, J. Bonjour, Confocal microscopy applied to capillary film measurements in a radial flat plate heat pipe made of silicon, Journal of Heat Transfer, accepted $16^{\text {th }}$ of july 2009.

[16] A. Faghri, Heat pipe science and technology, Taylor and Francis, London, 1995. 


\section{Figure captions}

Figure 1: Schematic of the FPHP

Figure 2: Temperature field along the FPHP $\left(H_{\mathrm{v}}=2 \mathrm{~mm}, q=7.5 \mathrm{~W} / \mathrm{cm}^{2}\right)$

Figure 3: Condenser thermal resistance versus the filling ratio $\left(H_{\mathrm{v}}=2 \mathrm{~mm}\right)$

Figure 4: Evaporator thermal resistance versus the filling ratio $\left(H_{\mathrm{v}}=2 \mathrm{~mm}\right)$

Figure 5: Overall thermal resistance versus the filling ratio $\left(H_{\mathrm{v}}=2 \mathrm{~mm}\right)$

Figure 6: Condenser thermal resistance versus the filling ratio $\left(H_{\mathrm{v}}=1 \mathrm{~mm}\right.$ and $\left.H_{\mathrm{v}}=2 \mathrm{~mm}\right)$

Figure 7: Condenser thermal resistance versus the filling ratio $\left(H_{\mathrm{v}}=5 \mathrm{~mm}\right)$

Figure 8: Evaporator thermal resistance versus the filling ratio $\left(H_{\mathrm{v}}=1 \mathrm{~mm}\right.$ and $\left.H_{\mathrm{v}}=2 \mathrm{~mm}\right)$

Figure 9: Evaporator thermal resistance versus the filling ratio $\left(H_{\mathrm{v}}=5 \mathrm{~mm}\right)$

Figure 10: Meniscus curvature radii along the FPHP; $H_{\mathrm{v}}=2 \mathrm{~mm}$ and $f_{\mathrm{r}}=9 \%$

Figure 11: Meniscus curvature radii along the FPHP; $H_{\mathrm{v}}=2 \mathrm{~mm}$ and $f_{\mathrm{r}}=13 \%$

Figure 12: Meniscus curvature radii along the FPHP $H_{\mathrm{v}}=1$ or $2 \mathrm{~mm}$

Figure 13: Distribution of the liquid inside a FPHP

Figure 14: Schematic of the meniscus

Figure 15: Meniscus shape on both sides of the FPHP for different vapour spaces $\left(a=2 \mathrm{~mm} ; \alpha_{0}=\right.$ $\left.\alpha_{1}=2^{\circ}\right)$

Figure 16: Meniscus curvature radius in the grooves versus $H_{\mathrm{v}}$

Figure 17: Theoretical and experimental meniscus curvature radii versus $V^{*}$ for different vapour space thicknesses 

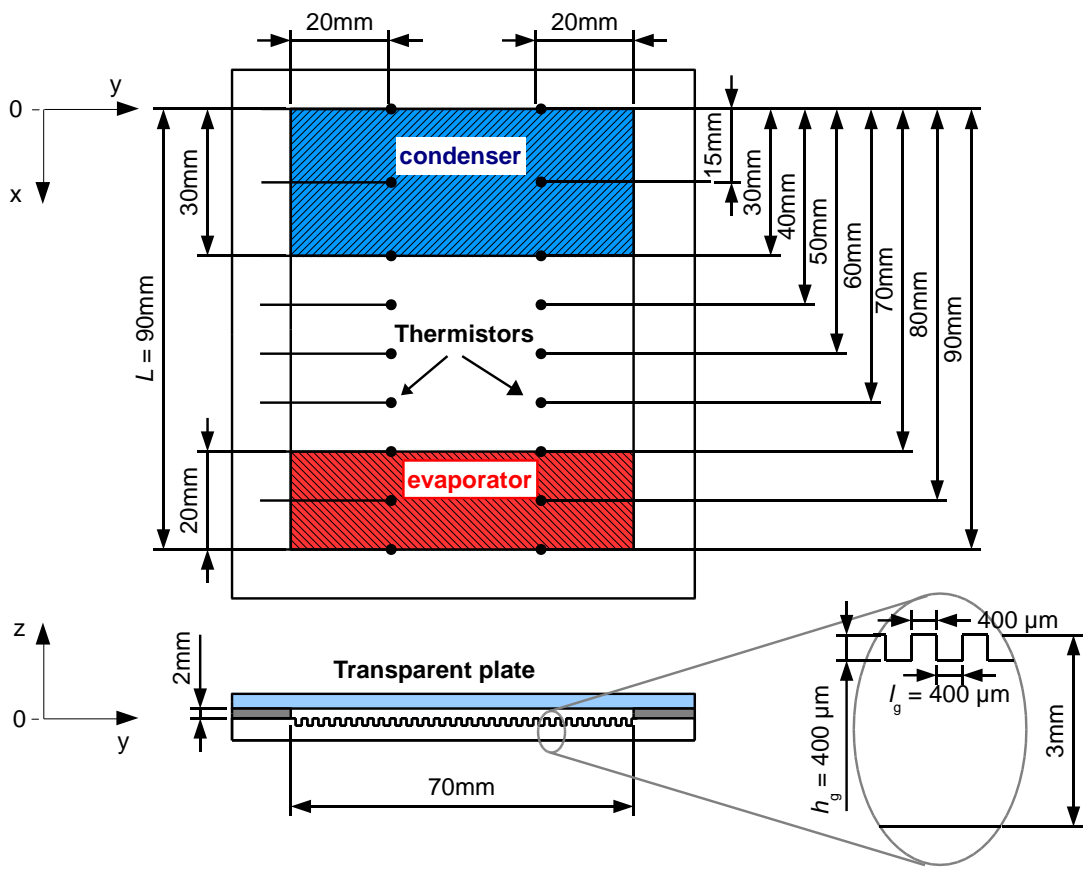

Figure 1: Schematic of the FPHP 


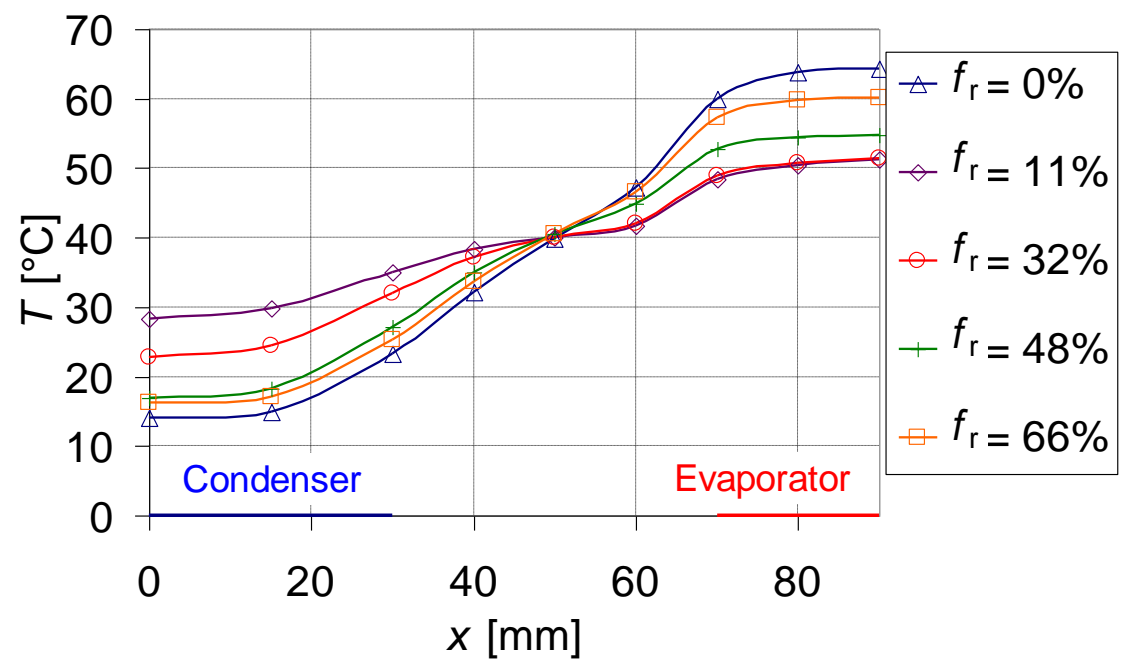

Figure 2: Temperature field along the FPHP $\left(H_{\mathrm{v}}=2 \mathrm{~mm}, q=7.5 \mathrm{~W} / \mathrm{cm}^{2}\right)$ 


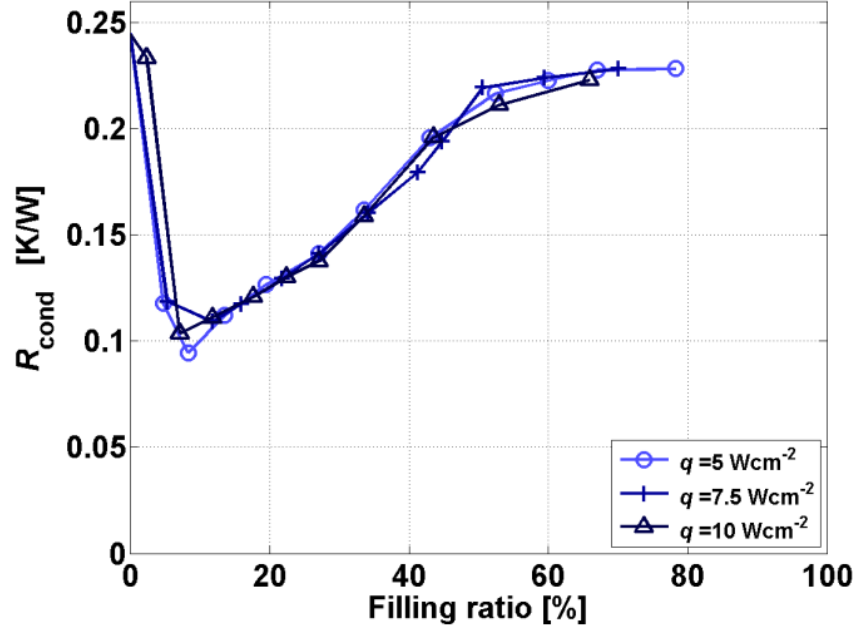

Figure 3: Condenser thermal resistance versus the filling ratio $\left(H_{\mathrm{v}}=2 \mathrm{~mm}\right)$ 


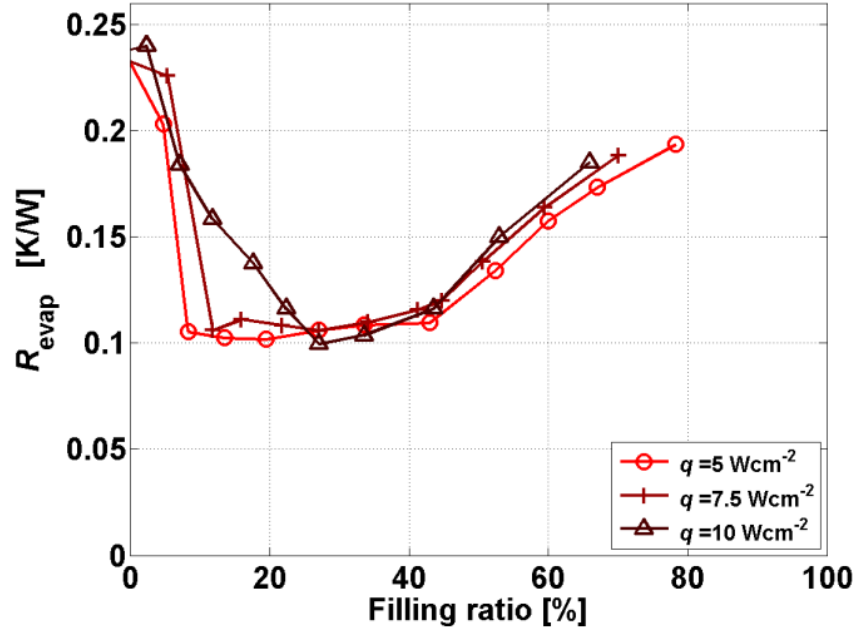

Figure 4: Evaporator thermal resistance versus the filling ratio $\left(H_{\mathrm{v}}=2 \mathrm{~mm}\right)$ 


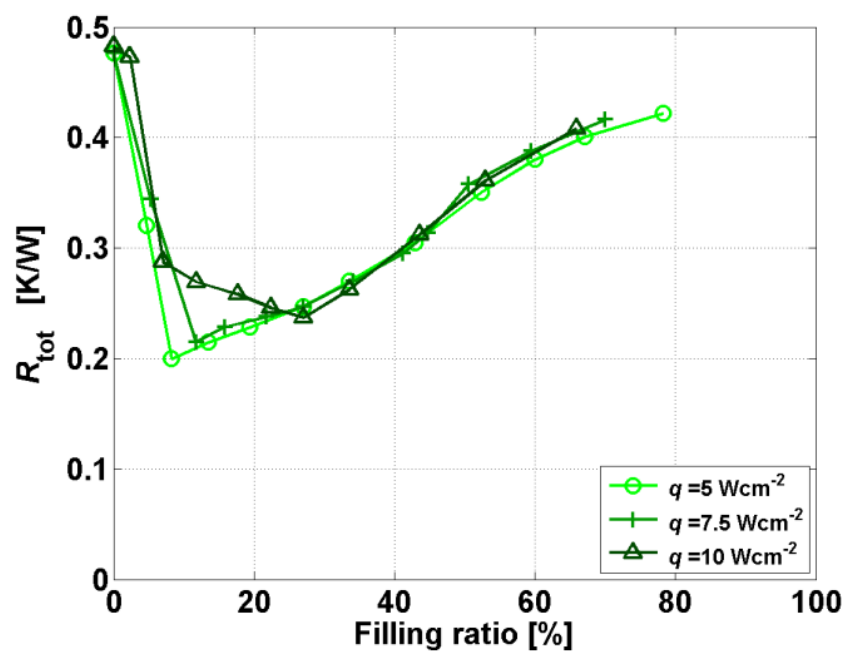

Figure 5: Overall thermal resistance versus the filling ratio $\left(H_{\mathrm{v}}=2 \mathrm{~mm}\right)$ 


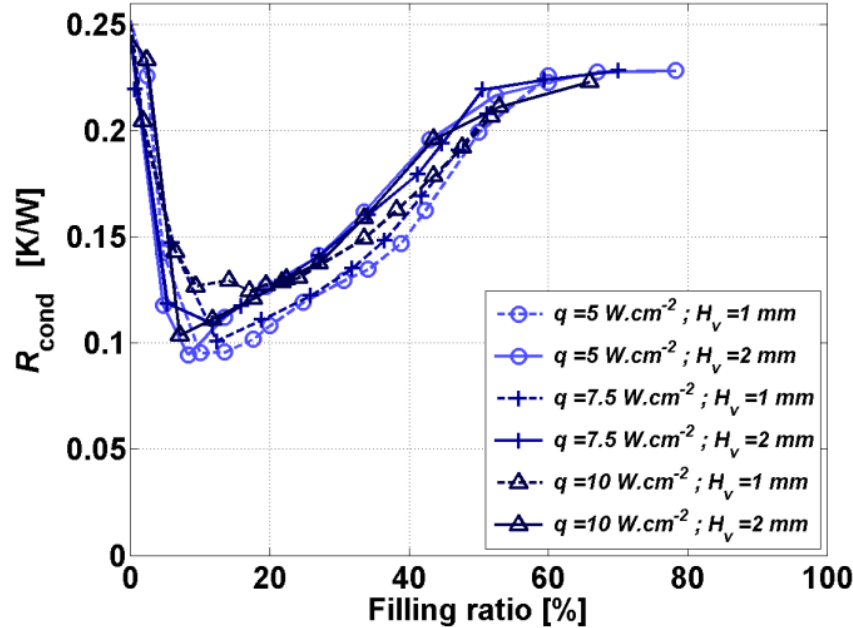

Figure 6: Condenser thermal resistance versus the filling ratio $\left(H_{\mathrm{v}}=1 \mathrm{~mm}\right.$ and $\left.H_{\mathrm{v}}=2 \mathrm{~mm}\right)$ 


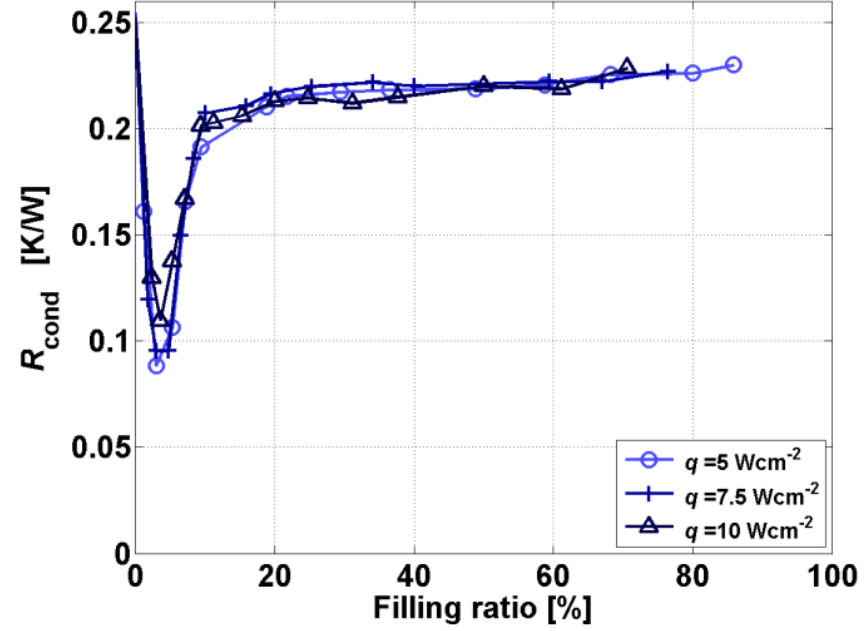

Figure 7: Condenser thermal resistance versus the filling ratio $\left(H_{\mathrm{v}}=5 \mathrm{~mm}\right)$ 


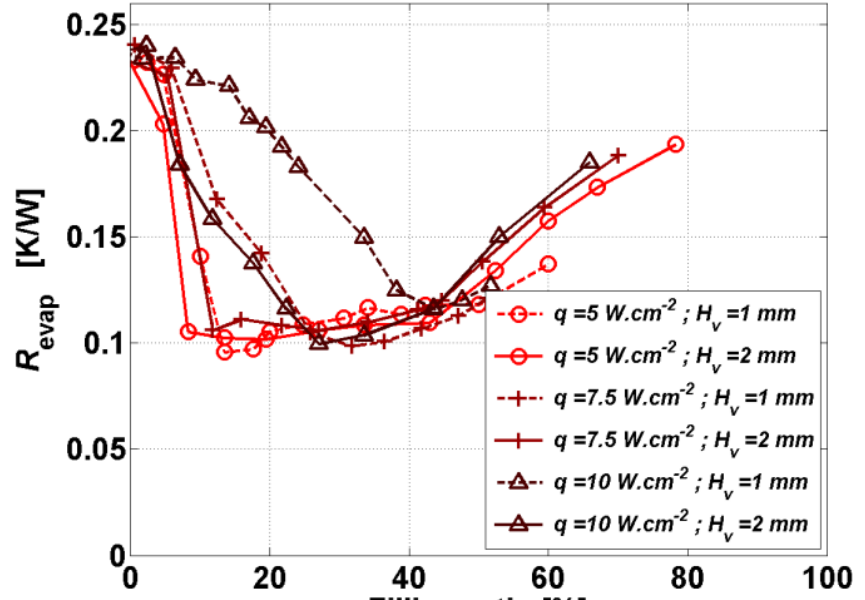

Figure 8: Evaporator thermal resistance versus the filling ratio $\left(H_{\mathrm{v}}=1 \mathrm{~mm}\right.$ and $\left.H_{\mathrm{v}}=2 \mathrm{~mm}\right)$ 


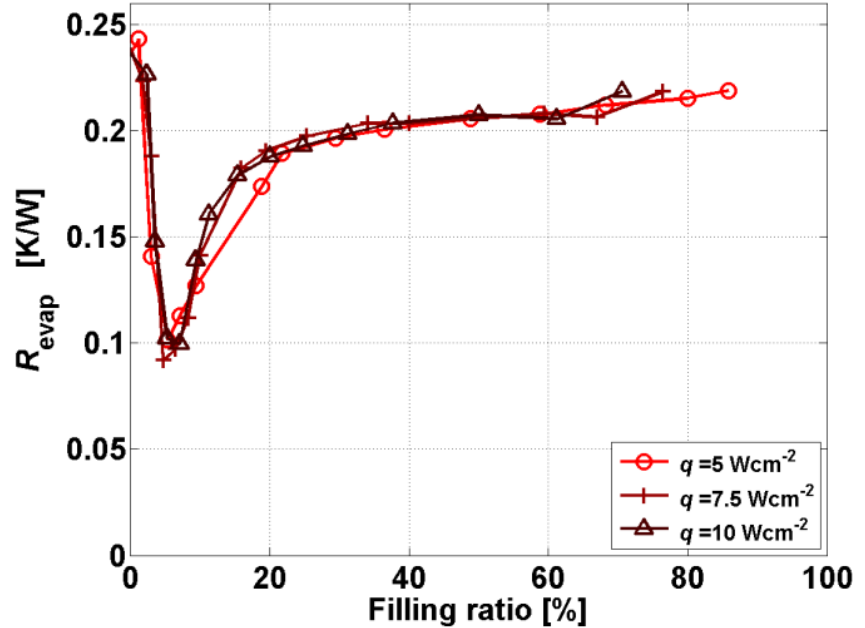

Figure 9: Evaporator thermal resistance versus the filling ratio $\left(H_{\mathrm{v}}=5 \mathrm{~mm}\right)$ 


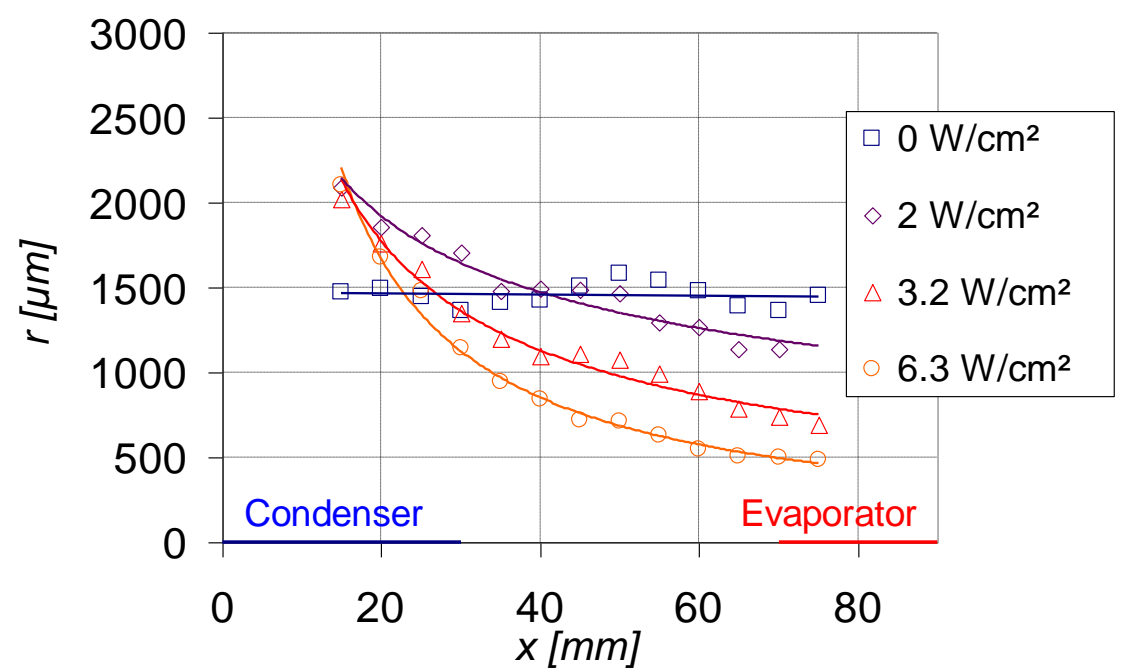

Figure 10: Meniscus curvature radii along the FPHP ; $H_{\mathrm{v}}=2 \mathrm{~mm}$ and $f_{\mathrm{r}}=9 \%$ 


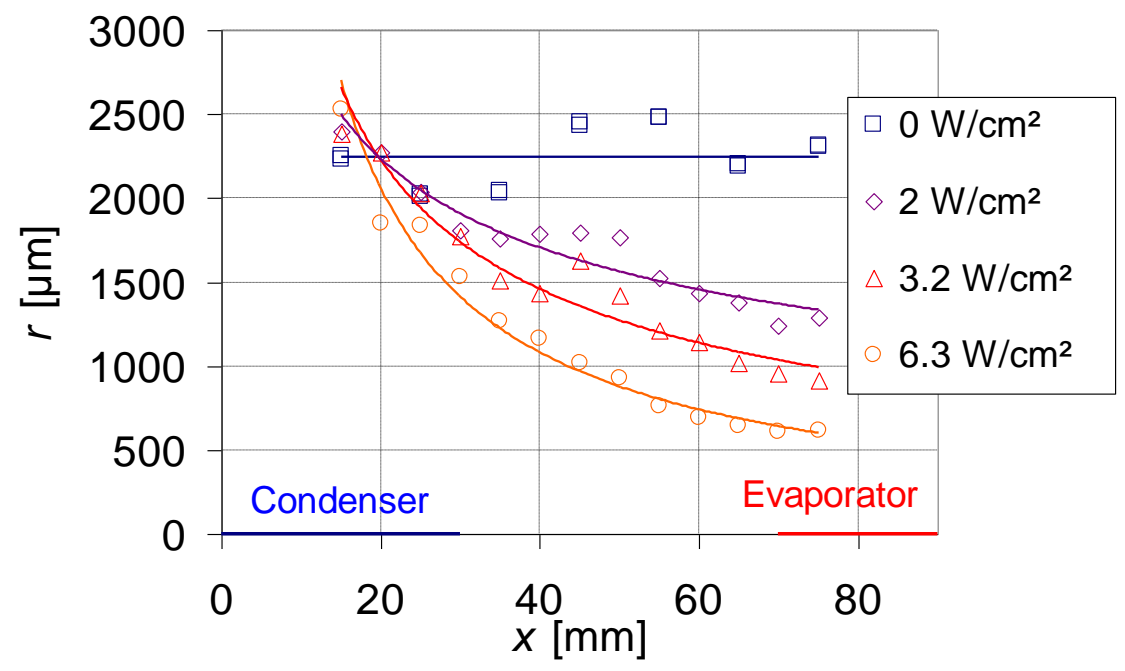

Figure 11: Meniscus curvature radii along the FPHP ; $H_{\mathrm{v}}=2 \mathrm{~mm}$ and $f_{\mathrm{r}}=13 \%$ 


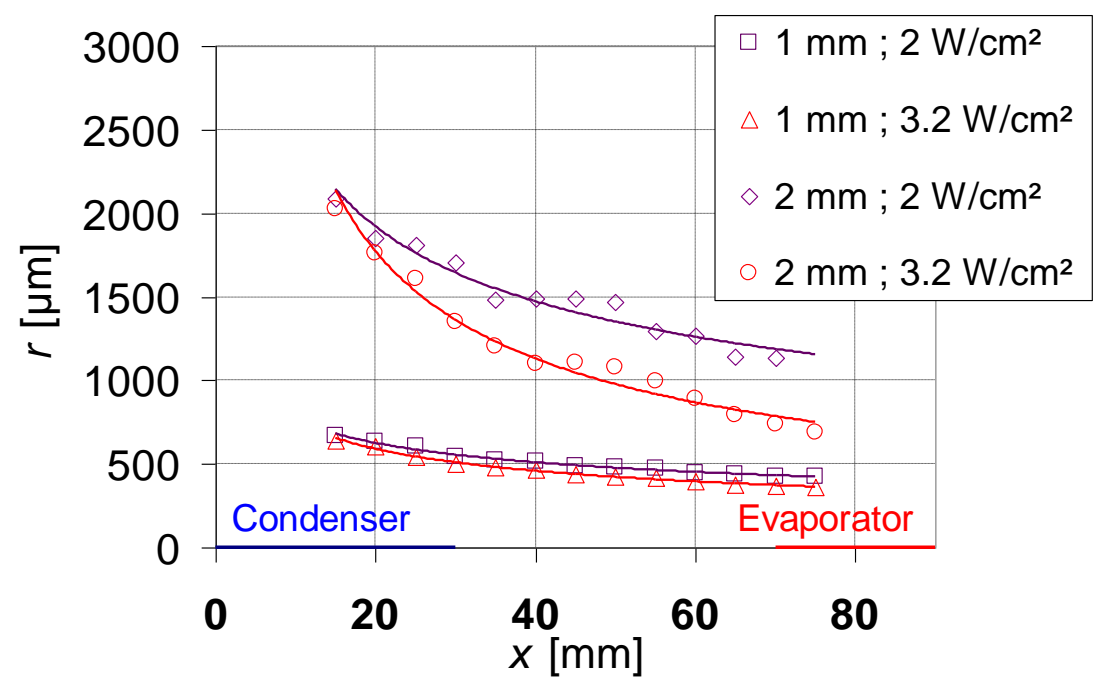

Figure 12: Meniscus curvature radii along the FPHP $H_{\mathrm{v}}=1$ or $2 \mathrm{~mm}$ 


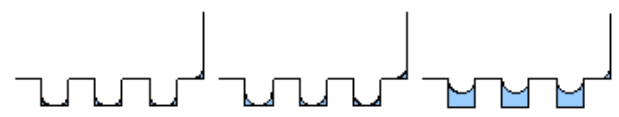

(a)

(b)

(c)

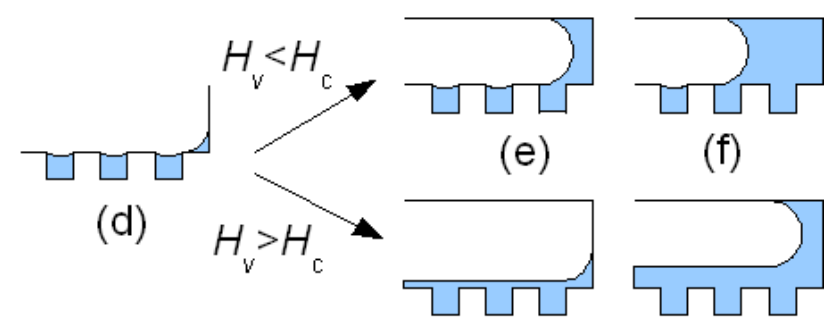

(e')

(f)

Figure 13: Distribution of the liquid inside a FPHP 


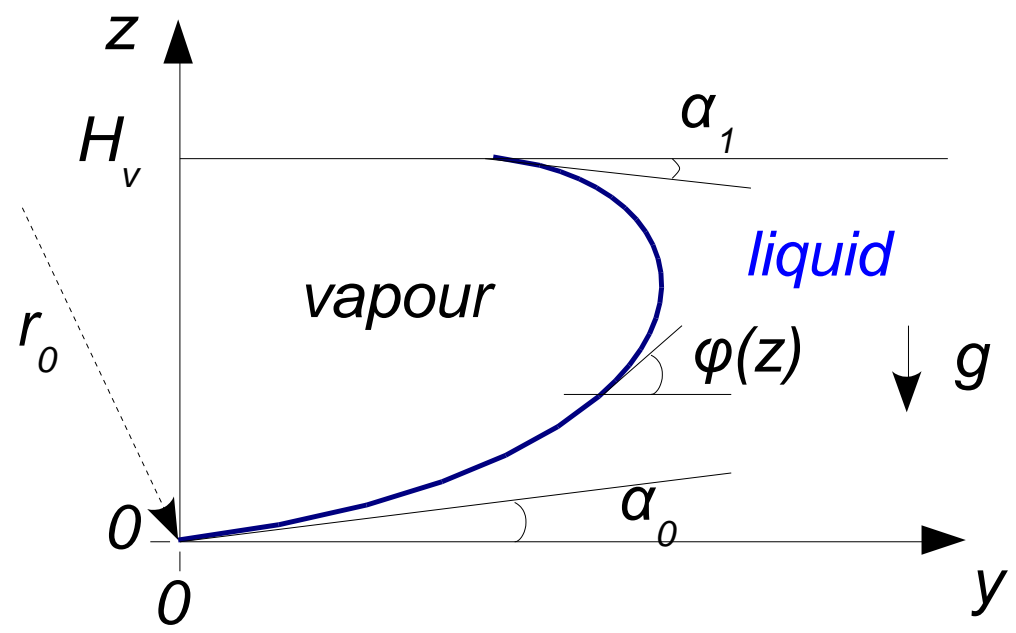

Figure 14: Schematic of the meniscus 


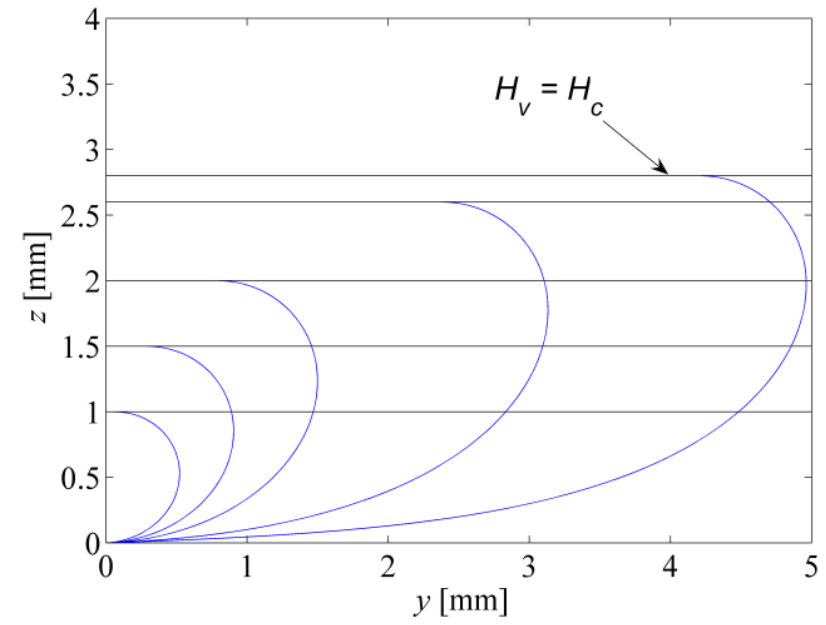

Figure 15: Meniscus shape on both sides of the FPHP for different vapour spaces $\left(a=2 \mathrm{~mm} ; \alpha_{0}=\alpha_{1}=2^{\circ}\right)$ 


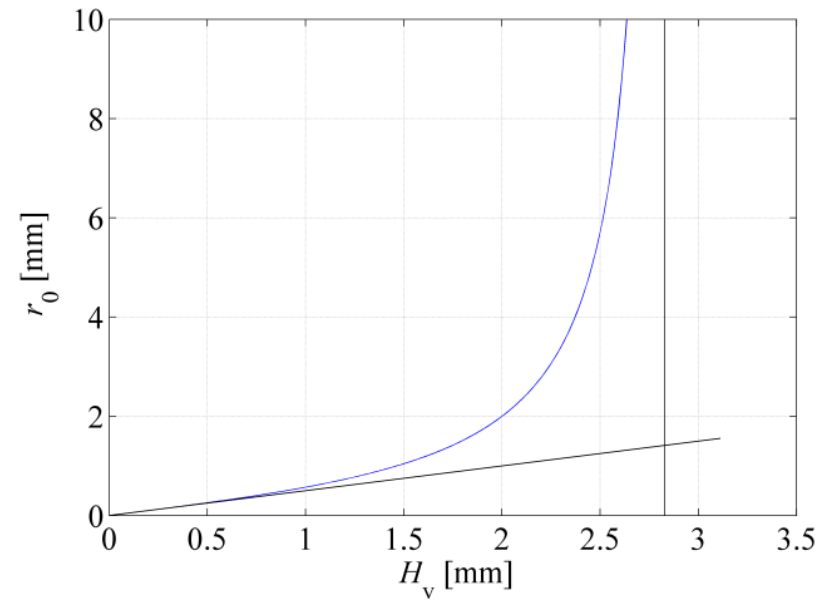

Figure 16: Meniscus curvature radius in the grooves versus $H_{\mathrm{v}}$ 


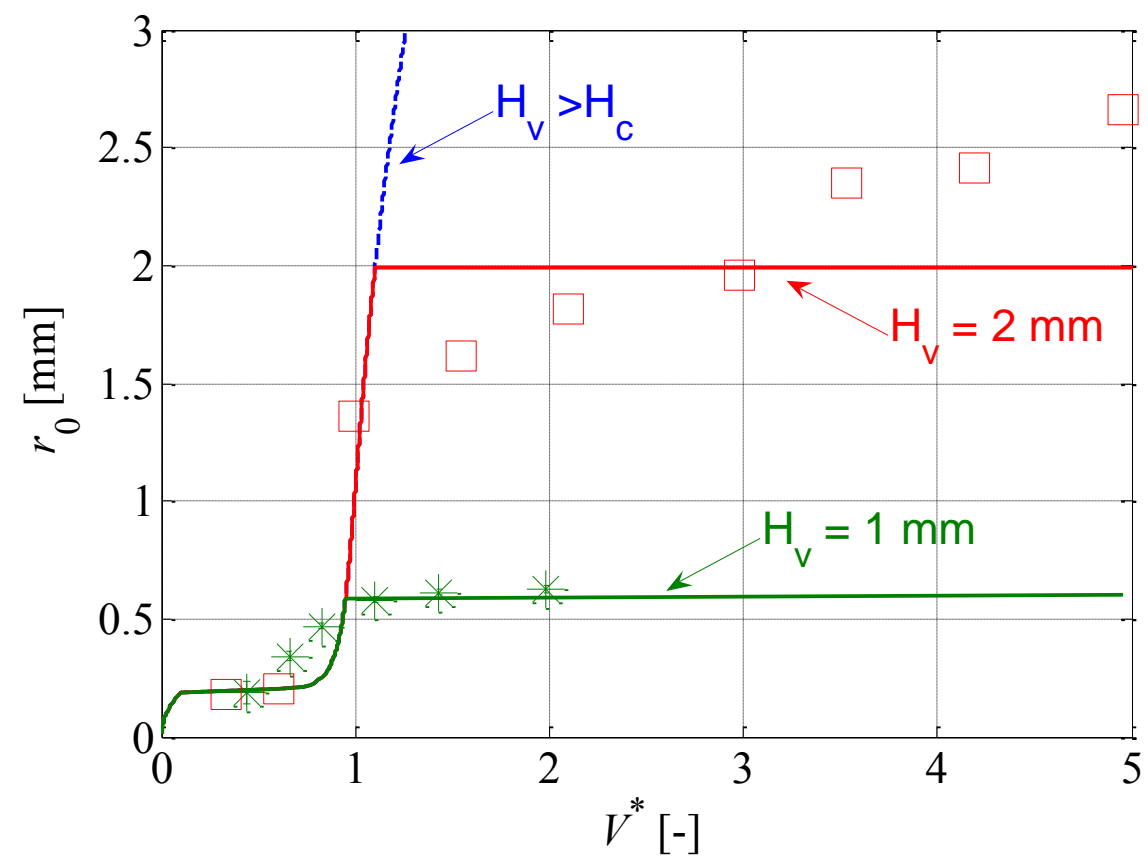

Figure 17: Theoretical and experimental meniscus curvature radii versus $V^{*}$ for different vapour space thicknesses 